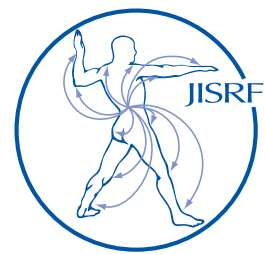

\title{
The Effect of Patellar Denervation by Circumpatellar Electrocautery on Anterior Knee Pain Following Total Knee Replacement - An Experimental Study
}

\author{
Zacharia $B^{1}$, Paul $M^{1}$
}

\section{Abstract}

Objectives: Anterior knee pain is a common problem in patients who have undergone TKR which causes dissatisfaction among them. There are Various methods for prevention of anterior knee pain following TKR .The objective of this study is to determine the effect of circumpatellar electrocautery on anterior knee pain following TKR and to compare the results with that of those patients who have undergone TKR without circumpatellar denervation.

Methods: This is a cohort study conducted in Dept. of Orthopedics, Govt. Medical College, Kozhikode,kerala, 2014. Total sample size was 90 .out of which 2 patients died during the study period. We lost follow up of 7 patients. Among the remaining 81 patients 42 had undergone TKR with circumpatellar denervation using electocautery and 39 without circumpatellar denervation. They were kept under follow up. Patients were followed up postoperatively at 1 month, 3 months, 6 months and at one year. At all postoperative visits, a clinical score was determined using the Knee Society score and the clinical anterior knee pain rating system described by Waters and Bentley.

Results: There is no statistically significant difference in AKP score between both groups.There is a statistically significant difference in the knee society score at 1 st month(p value <.001). But there is no difference on further follow up visits.

Conclusion: There is no statistically significant difference between final outcome of patients who underwent patella denervation using circumpatellar electrocauterisation and those without denervation with respect to anterior knee pain among patients who have undergone TKR.

Keywords: total knee arthroplasty; anterior knee pain; Circumpatellar denervation Level of Evidence: AAOS Therapeutic Level III

1 Professor Balaji Zacharia; Manu Paul Govt. Medical College, Dept. Of Orthopedics, Kozhikkode (PO), Kerala, India, PIN 673008

(Direct reprint requests to Balaji Zacharia)
(C) 2017 Zacharia, Paul. All rights reserved.

Authors retain copyright and grant the journal right of first publication with the work. Reconstructive Review is an open access publication and follows the Creative Commons Attribution-NonCommercial CC BY-NC. This

license allows anyone to download works, build upon the material, and share them with others for non-commercial purposes as long as they credit the senior author, Reconstructive Review, and the Joint Implant Surgery \& Research Foundation (JISRF). An example credit would be: "Courtesy of (senior author's name), Reconstructive Review, JISRF, Chagrin Falls, Ohio". 


\section{Introduction}

Anterior knee pain is a common problem in patients who have undergone TKR which causes dissatisfaction among them. The reported incidence of anterior knee pain is about $8 \%$ [1]. Patellar denervation using circumpatellar electrocautery is a reasonable option in preventing anterior knee pain without any extra cost or technical difficulties.

The etiology of anterior knee pain after replacement is unknown but is thought to be multi-factorial and related to the patella-femoral joint. There are many predictors for anterior knee pain. The young age female sex, severe pain before surgery; low pain threshold is the non-modifiable predictors $[\underline{2}, \underline{3}, \underline{4}]$. The modifiable predictors are anxiety, depression, problems of pain processing and preoperative expectations []․

Nerve endings cut during surgery can regenerate and gets blocked in the scar tissue; a painful neuroma can be formed. Hypoxia of nerves produced due to compression between bone, ligaments or the scar tissue leads to abnormal signal conduction to the CNS which can be felt as an abnormal tingling sensation []. The cause of anterior knee pain after TKR can be divided into functional and mechanical problems. But in every case an infection should be ruled out.

There are many functional causes for anterior knee pain following TKR. Quadriceps weakness is a major problem after TKR. It can lead to patellar mal-tracking and quadriceps avoidance gait which is characterized by compensatory increased forward inclination of the trunk due to quadriceps weakness[ $[\underline{7}, \underline{8}, \underline{9}]$. Another cause for knee pain is knee spine syndrome due to pathologies in lumbar spine causing lordosis and increased pelvic tilt. Patello-femoral instability and mal-tracking is the main cause for postoperative pain and functional limitations in the joint [10]. It can be caused by insufficient soft tissue balancing, component positioning or design of implant $[\underline{11}, 12]$. Femoral components with a posterior centre of rotation have a favorable influence on anterior knee pain [13]. It was thought that posterior stabilized (PS) prosthesis design leads to lower patella-femoral joint pressures than a cruciate-retaining (CR) design [14]. But no difference was found with regard to postoperative pain between CR prostheses and PS designs in recent studies [15].

Patella baja can cause anterior knee pain but incidence is low [16]. A progressive degenerative arthritic process of patella due to increased pressure on it by the knee prosthesis can cause anterior knee pain [12]. An increased internal rotation mal alignment of either tibial or femoral component or both can lead to lateral tilt of patella and anterior knee pain [17]. The patello-femoral joint contact pressure is increased due to the posterior subluxation of tibio femoral joint [18]. Avascular necrosis or a transient ischemia can produce localized pain over the patella [19]. Patellar fracture is a rare complication after TKR [20]. Patellar clunk and Synovial hyperplasia can cause anterior knee pain $[\underline{21}, \underline{22}]$.

There are various methods for prevention of anterior knee pain following TKR like patelloplasty patellar denervation, patellar resurfacing, avoiding patella malt racking, proper implant selection and component position [23] Routine patellar resurfacing appears to be an option to reduce patello femoral-related pain. But AKP may still be identified in $5 \%$ of patients who undergo primary TKR with patellar resurfacing [24].There are evidences to suggest that routine patellar resurfacing is not needed in order to preserve the patella and to reduce the risk of reoperation in resurfaced patients [25].

Immunohistochemical studies have confirmed the presence of substance-P nociceptive afferent fibers in the peripatellar soft tissues [26]. Hence It is suggested that circumpatellar electrocautery would lead to partial denervation and improved pain relief when patellar resurfacing is not possible. It was thought that primary TKR with circumpatellar electrocautery would lead to partial denervation and improved pain relief compared with no electrocautery. As our institution is catering patients from low and middle socioeconomic status population we do not routinely resurface the patella. The primary objective of this study is to determine the clinical effect of circumpatellar electrocautery on anterior knee pain following TKR and to compare the results with that of those patients who have undergone TKR without circumpatellar denervation.

\section{Materials and Methods}

This is a cohort study conducted in Dept. of Orthopedics, Govt. Medical College, Kozhikode,kerala,India during the period January 2012 to December 2014 after getting institutional research committee and ethics committee approval. All patients above the age of 55 who have undergone TKR at our institution during above period were included after getting written informed consent. Those patients with inflammatory arthritis, secondary osteoarthritis of knee following trauma.TKR after high tibial osteotomy and patients with any medical disorder which restricted them from walking were excluded from our study. Those patients who have undergone total hip replacement (THR) and revision TKR were also excluded.

Those patients who have met inclusion criteria and those have given written informed consent were included 
in the study. Total sample size was 90 .out of which 2 patients died during the study period. We lost follow up of 7 patients. Among the remaining 81 patients 42 had undergone TKR with circumpatellar denervation using electocautery and 39 without circumpatellar denervation. Total knee replacement was done using standard surgical technique in both groups.

They were kept under follow up. Patients were followed up postoperatively at 1 month, 3 months, 6 months and at one year. At all postoperative visits, a clinical score was determined using the Knee Society score and the clinical anterior knee pain rating system described by Waters and Bentley $[\underline{27}, \underline{28}]$.

\section{The clinical anterior knee pain rating system described by Waters and Bentley \\ Grade Rating Description \\ $0 \quad$ No pain \\ I Mild pain which does not intrude on daily activities \\ II Moderate pain which is a nuisance \\ III Severe pain}

Table 1: Age distribution

\begin{tabular}{|c|c|c|c|c|c|c|}
\hline \multirow{2}{*}{$\begin{array}{c}\text { Age } \\
\text { (years) }\end{array}$} & \multicolumn{2}{|c|}{$\begin{array}{c}\text { Patella } \\
\text { denervation +ve }\end{array}$} & \multicolumn{2}{c|}{$\begin{array}{c}\text { Patella } \\
\text { denervation -ve }\end{array}$} & \multicolumn{2}{c|}{ Total } \\
\cline { 2 - 7 } & No. & $\%$ & No. & $\%$ & No. & $\%$ \\
\hline $55-59$ & 18 & 42.9 & 13 & 33.3 & 31 & 38.3 \\
\hline $60-69$ & 19 & 45.2 & 20 & 51.3 & 39 & 48.1 \\
\hline $\begin{array}{c}70 \text { and } \\
\text { above }\end{array}$ & 5 & 11.9 & 6 & 15.4 & 11 & 13.6 \\
\hline Total & 42 & 100 & 39 & 100 & 81 & 100 \\
\hline
\end{tabular}

Chart 1: Age distribution

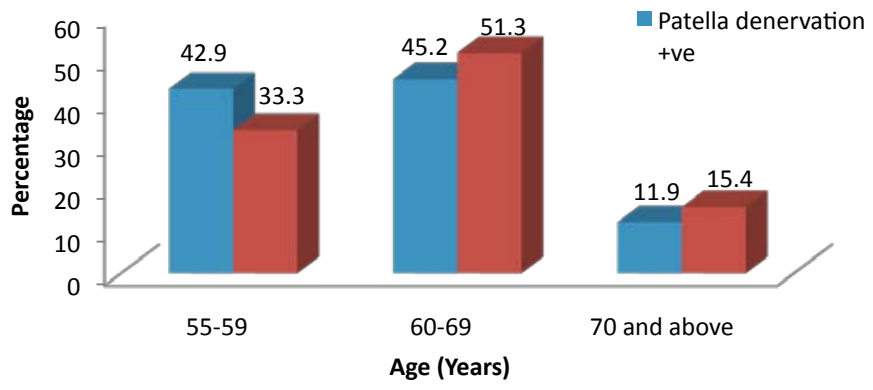

Table 2: Anterior knee pain score. Independent samples ' $t$ ' test.

\begin{tabular}{|c|c|c|c|}
\hline \multirow{2}{*}{ Followup } & \multicolumn{2}{|c|}{ Average AKP score } & \multirow{2}{*}{$\begin{array}{c}\text { p } \\
\text { value }\end{array}$} \\
\cline { 2 - 3 } & $\begin{array}{c}\text { Patellar } \\
\text { denervation +ve }\end{array}$ & $\begin{array}{c}\text { Patellar } \\
\text { denervation -ve }\end{array}$ & \\
\hline 1 month & $2.00(0.49)$ & $1.92(0.62)$ & 0.54 \\
\hline 3 months & $1.38(3.62)$ & $1.49(0.50)$ & 0.40 \\
\hline 6 months & $0.98(0.71)$ & $0.97(0.54)$ & 0.99 \\
\hline 12 months & $0.81(0.70)$ & $0.64(0.54)$ & 0.23 \\
\hline
\end{tabular}

\section{Chart 2: AKP score}

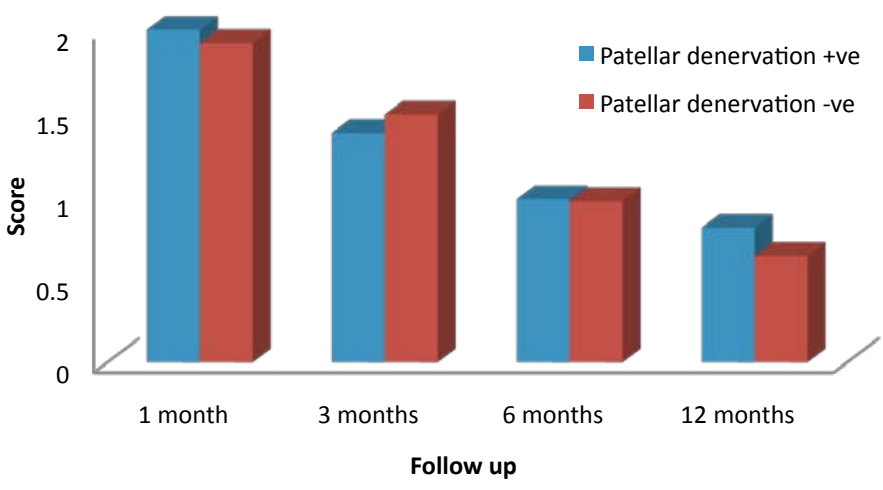

circumpatellar denervation among patients who have undergone total knee replacement.

In our study, anterior knee pain is graded using anterior knee pain grading system of Waters and Bentley. Anterior knee pain score was improving in both groups but there was no significant difference between the two groups. Knee society score was compared between the two groups. 
Table 3: Anterior society score. Independent samples 't' test.

\begin{tabular}{|c|c|c|c|}
\hline \multirow{2}{*}{ Followup } & \multicolumn{2}{|c|}{ Average AKP score } & \multirow{2}{*}{$\begin{array}{c}\text { p } \\
\text { value }\end{array}$} \\
\cline { 2 - 3 } & $\begin{array}{c}\text { Patellar } \\
\text { denervation +ve }\end{array}$ & $\begin{array}{c}\text { Patellar } \\
\text { denervation -ve }\end{array}$ & \\
\hline 1 month & $3.02(0.41)$ & $3.41(0.50)$ & $<0.001$ \\
\hline 3 months & $1.98(0.81)$ & $2.28(0.76)$ & 0.08 \\
\hline 6 months & $1.43(0.63)$ & $1.38(0.59)$ & 0.75 \\
\hline 12 months & $1.21(0.56)$ & $1.18(0.50)$ & 0.77 \\
\hline
\end{tabular}

\section{Chart 3: Knee society score}

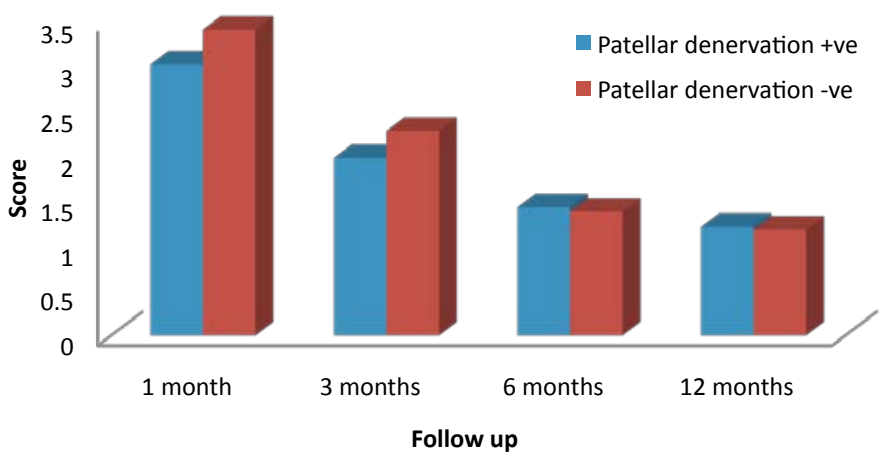

Table 4: Improvement in AKP score on each visit (Average AKP score paired difference). Paired sample ' $t$ ' test.

\begin{tabular}{|c|c|c|c|c|c|c|}
\hline & \multicolumn{3}{|c|}{ Patellar denervation +ve } & \multicolumn{3}{c|}{ Patellar denervation -ve } \\
\cline { 2 - 7 } & Mean & SD & p value & Mean & SD & p value \\
\hline $\begin{array}{c}1-3 \\
\text { months }\end{array}$ & 0.62 & 0.54 & $<0.001$ & 0.44 & 0.60 & $<0.001$ \\
\hline $\begin{array}{c}1-6 \\
\text { months }\end{array}$ & 1.02 & 0.56 & $<0.001$ & 0.95 & 0.76 & $<0.001$ \\
\hline $\begin{array}{c}1-12 \\
\text { months }\end{array}$ & 1.19 & 0.63 & $<0.001$ & 1.28 & 0.72 & $<0.001$ \\
\hline
\end{tabular}

Table 5: Improvement in Knee society score on each visit (Average knee score paired difference). Paired sample ' $t$ ' test.

\begin{tabular}{|c|c|c|c|c|c|c|}
\hline & \multicolumn{3}{|c|}{ Patellar denervation +ve } & \multicolumn{3}{|c|}{ Patellar denervation -ve } \\
\cline { 2 - 7 } & Mean & SD & p value & Mean & SD & p value \\
\hline $\begin{array}{c}1-3 \\
\text { months }\end{array}$ & 1.05 & 0.73 & $<0.001$ & 1.13 & 0.57 & $<0.001$ \\
\hline $\begin{array}{c}1-6 \\
\text { months }\end{array}$ & 1.59 & 0.59 & $<0.001$ & 2.03 & 0.58 & $<0.001$ \\
\hline $\begin{array}{c}1-12 \\
\text { months }\end{array}$ & 1.81 & 0.50 & $<0.001$ & 2.23 & 0.63 & $<0.001$ \\
\hline
\end{tabular}

There was a statistically significant difference at one month but later this difference disappeared. There was a better knee society score among patella denervation group at 1 st month.

In a study conducted by Balinga $\mathrm{S}$ et al, the outcome following circumpatellar denervation was assessed based on Oxford knee score (OKS) and anterior knee pain using Visual analog scale (VAS). This study showed statistically significant improvement in the OKS and VAS among the patella denervation group [29]. But when the post operative VAS score is compared with the pre op VAS score there was no significant difference in mean improvement in VAS score. Using logistic regression analysis, they found that a low VAS score preoperatively was the predictor of better VAS score than denervation using electro cautery. In another study conducted on 50 patients with bilateral TKR (One side patellar denervation done).

They found out that there was no statistical significant improvement in KSS or WOMAC score with patella denervation [30].

But another study conducted by HPW Van Jonberger in 2008 concluded that in the absence of patellar resurfacing, patellar denervation using electrocautery improves the outcome [31]. A total of 131 patients received patellar denervation and another 131 didn't receive denervation. The relative risk reduction from electrocautery was $40 \%$. The intervention group had a better WOMAC score. (16.3 Vs $21.6, \mathrm{p}$ value 0.04$)$. Knee society score (92.4 Vs 90.4, p value 0.14 ) was similar in both group. But a randomized control trial conducted by the same author showed that the initial clinical improvement with electrocautery denervation of patella in TKR is not maintained at a mean follow up of 3.7 years [32].

MA Altay and C. Erturk conducted a randomized control study in 2012 which showed that there is a definite advantage with patellar denervation [33]. There were 35 knees each in intervention and control group. In a meta analysis conducted by Tao Cheng et al concluded that there is no strong evidence either for or against circum patellar electrocauterisation compared with non electrocautery in TKR [34]. The clinical outcome of 131 patients followed for more than 9 years were retrospectively assessed and found that patellar non resurfacing techniques including patelloplasty and circumpatellar denervation are similar to patellar resurfacing [35].

So the available studies give conflicting results regarding the effect of patellar denervation. Our study shows that there is no advantage of doing patellar denervation on anterior knee pain or knee society score. This may be due to the fact that etiology of anterior knee pain is multi-factorial. Hence all the causes cannot be addressed by the patel- 
lar denervation alone. So we cannot prevent anterior knee pain by doing patellar denervation alone. Apart from factors described in introduction, preoperative expectations and patient education have influence on the postoperative outcome as shown by focused group discussions conducted by us in our TKR patients.

There are some limitations in our study. Here the sample size is small and our follow up period is short. Preoperative severity of knee pain was not included in study. It is a determinant of severity postoperative knee pain.

\section{Conclusion}

There is no statistically significant difference between final outcome of patients who underwent patella denervation using circumpatellar electrocauterisation and those without denervation with respect to anterior knee pain among patients who have undergone TKR.

\section{Disclosure}

The authors declare that there is no conflict of interest regarding the publication of this paper. For full disclosures refer to last page of this journal.

\section{References:}

1. After total knee arthroplasty: gender-related differences. J Arthroplasty 2011; 26(8):1475-1480

2. Bonnin MP, Basiglini L, Archbold HA. What are the factors of residual pain after uncomplicated TKA? Knee Surg Sports Traumatol Arthrosc 2011;19(9):14111417.

3. Liu SS, Buvanendran A, Rathmell JP, Sawhney M, Bae JJ, et al. Predictors for moderate to severe acute postoperative pain after total hip and knee replacement. Int Orthop 2012; 36(11):2261-2267.

4. Schnurr C, Jarrous M, Güdden I, Eysel P, König DP. Pre-operative arthritis severity as a predictor for total knee arthroplasty patients' satisfaction. Int Orthop 2013;37(7):1257-1261.

5. Forsythe ME, Dunbar MJ, Hennigar AW, Sullivan MJ, Gross M. Prospective relation between catastrophizing and residual pain following knee arthroplasty: twoyear follow-up. Pain Res Manag 2008; 13(4): 335-341.

6. Anterior knee pain after a total knee arthroplasty: What can cause this pain. World Journal of Orthopedics 2014; 5(3): 163-170.

7. Saleh KJ, Lee LW, Gandhi R, Ingersoll CD, Mahomed NN et al. Quadriceps strength in relation to total knee arthroplasty outcomes. Instr Course Lect 2010; 59:119- 130

8. Lin F, Wilson NA, Makhsous M, Press JM, Koh JL, Nuber GW, Zhang LQ. In vivo patellar tracking induced by individual quadriceps components in individuals with patellofemoral pain. J Biomech 2010; 43(2):235-241.

9. LiK, AcklandDC, McClelland JA,Webster KE, Feller JA, de Steiger R, Pandy MG. Trunk muscle action compensates for reduced quadriceps force during walking after total knee arthroplasty. Gait Posture 2013; 38:79-85.

10. Tsuji T, Matsuyama Y, Goto M, Yimin Y, Sato K, Hasegawa Y, Ishiguro N. Kneespine syndrome: correlation between sacral inclination and patellofemoral joint pain. J Orthop Sci 2002; 7(5):519-523.

11. Motsis EK, Paschos N, Pakos EE, Georgoulis AD. Patellar instability after total knee arthroplasty. J Orthop Surg (Hong Kong) 2009; 17:351-357.

12. Seil R, Pape D. Causes of failure and etiology of painful primary total knee arthroplasty. Knee Surg Sports Traumatol Arthrosc 2011; 19(9):1418-1432.

13. van Jonbergen HP, Reuver JM, Mutsaerts EL, Poolman RW. Determinants of anterior knee pain following total knee replacement: a systematic review. Knee Surg Sports Traumatol Arthrosc 2012 Nov.18. [Epub ahead of print] PMID:23160846.
14. Bacher $\mathrm{C}$ et al. Posterior stabilized TKA reduce patellofemoral contact pressure compared with cruciate retaining TKA in vitro. Knee Surg Sports Traumatol Arthrosis 2009; 17(1): 1159-1165.

15. Li N, Tan Y, Deng Y, Chen L (2012) Posterior cruciate-retaining versus posterior stabilized total knee arthroplasty: a meta-analysis of randomized controlled trials. Knee Surg Sports Traumatol Arthrosc

16. Chonko DJ, Lombardi AV Jr, Berend KR. Patella baja and total knee arthroplasty (TKA): etiology, diagnosis, and management. Surg Technol Int 2004; 12:231-238.

17. Bhattee G,Moonot P, Govindaswamy R, Pope A, Fiddian N, Harvey A. Does malrotation of components correlate with patient dissatisfaction following secondary patellar resurfacing? The Knee 2013; 21(1): 247-251.

18. PagnanoMW, Hanssen AD, Lewallen DG, Stuart MJ. Flexion instability after primary posterior cruciate retaining total knee arthroplasty. Clin Orthop 1998; 356:39-46

19. Wetzner SM, Bezreh JS, Scott RD, Bierbaum BE, Newberg AH. Bone scanning in the assessment of patellar viability following knee replacement. Clin Orthop Relat Res. 1985;199:215-219

20. Ortiguera CJ, Berry DJJ Patellar fracture after total knee arthroplasty Bone Joint Surg Am. 2002 Apr; 84-A(4):532-40

21. Lucas TS, DeLuca PF, Nazarian DG, Bartolozzi AR, Booth RE Jr. Arthroscopic treatment of patellar clunk. Clin Orthop 1999; 367: 226-229.

22. Lützner J, Hartmann A, Dinnebier G, Spornraft-Ragaller P, Hamann C, Kirschner $\mathrm{S}$. Metal hypersensitivity and metal ion levels in patients with coated or uncoated total knee arthroplasty: a randomised controlled study. Int Orthop 2013; 37(1): 1925-1931.

23. A. Baco, G. Bentley and H. Alyawer patelloplasty in knee replacement JBone Joint Surg Br 2006

24. Gupta R, Canty S, Ryan W. Anterior knee pain following total knee replacement caused by isolated pagets disease of patella. The international Journal of Orthopaedic surgery 2007; 9(2).

25. Feller JA, Bartlett RJ, Lang DMPatellar resurfacing versus retention in total knee arthroplasty. J Bone Joint Surg Br. 1996 Mar;78(2):226-8.

26. Wojtys EM, Beaman DN, Glover RA, Janda D. Innervation of the human knee joint by substance P fibres. Arthroscopy 1990; 6: 254-63.

27. Insall JN, Dorr LD, Scott RD, Scott WN. Rationale of the Knee Society clinical rating system. Clin Orthop Relat Res 1989(248):13-4.

28. Waters TS, Bentley G. Patellar resurfacing in total knee arthroplasty: a prospective, randomized study. J Bone Joint Surg [Am] 2003; 85-A:212-17.

29. Baliga CJ, McNair KJ, Barnett J, MacLeod RW, Humphry D. Does circumpatellar electrocautery improve the outcome after total knee replacement? A prospective, randomised, blinded controlled trials. Finlayson. J Bone Joint Surg Br 2012; 94-B: 1228-33.

30. Yim SJ, Jang MS, Kim WJ, Lee SH, Kang HK. The Effect of Electrocautery around the Patellar Rim in Patellar Non-Resurfacing Total Knee Arthroplasty. Knee Surg Relat Res 2012;24(2):104-107.

31. van Jonbergen HPW, Scholtes VAB, van Kampen A, Poolman RW. A randomised, controlled trial of circumpatellar electrocautery in total knee replacement without patellar resurfacing. J Bone Joint Surg [Br] 2011; 93-B: 1054-9.

32. van Jonbergen HP, Scholtes VA, Poolman RW A randomised, controlled trial of circumpatellar electrocautery in total knee replacement without patellar resurfacing: a concise follow-up at a mean of 3.7 years. Bone Joint J. 2014 Apr;96$\mathrm{B}(4): 473-8$.

33. Altay MA1, Ertürk C, Altay N, Akmeşe R, Işıkan UE. Patellar denervation in total knee arthroplasty without patellar resurfacing: a prospective, randomized controlled study. Orthop Traumatol Surg Res 2012; 98(4):421-5.

34. Cheng T, Zhu C, Guo Y, Shi S, Chen D, Zhang X Patellar denervation with electrocautery in total knee arthroplasty without patellar resurfacing: a meta-analysis. Knee Surg Sports Traumatol Arthrosc. 2014 Nov;22(11):2648-54

35. Li B1, Bai L, Fu Y, Wang G, He M, Wang JComparison of clinical outcomes between patellar resurfacing and nonresurfacing in total knee arthroplasty: retrospective study of 130 cases. J Int Med Res. 2012;40(5):1794-803. 